\title{
How Social Innovation 'Came to Be': Tracing the Evolution of a Contested Concept
}

\author{
NOORSEHA AYOB*, SIMON TEASDALE** AND KYLIE FAGAN*** \\ * Yunus Centre for Social Business and Health, Glasgow Caledonian University, Glasgow. \\ email: noorseha.ayob@gcu.ac.uk \\ ** Yunus Centre for Social Business and Health, Glasgow Caledonian University, Glasgow. \\ email: simon.teasdale@gcu.ac.uk \\ *** Yunus Centre for Social Business and Health, Glasgow Caledonian University, Glasgow. \\ email: kylie.fagan@gcu.ac.uk
}

\begin{abstract}
Social innovation is a contested concept with multiple meanings that have implications beyond academia. It is not a new term - its sociological heritage can be dated to the late nineteenth century. However, until the twenty-first century the concept was sparsely utilised, and, despite its current popularity among policy makers in Europe and the United States, remains largely ignored by social policy researchers. Through bibliometric analysis we identify the most influential articles on social innovation and explore how these have conceptualised the term. We show that over time social innovation has taken on a set of meanings far removed from its sociological roots. In particular we identify a weak tradition that sees social innovation as any increase in aggregate individual utility arising from an innovation, and a strong tradition that focuses on the process of collaboration between different groups and the restructuring of power relations. We conclude by outlining implications for social policy research.
\end{abstract}

\section{Introduction}

In recent years the concept of social innovation has become central to policy debates at national and supranational levels. In the United States, President Obama established the Office of Social Innovation and Civic Participation within the White House in 2009 ostensibly to engage citizens and civil society to find new ways to solve social problems. At the European level, social innovation cuts across a range of policy areas and was developed under the Social Innovation Initiative with the aim of mainstreaming social innovation policies through the Horizon 2020 strategic framework for research and innovation (Massey and JohnstonMiller, 2014). Academic research precedes the policy interest in social innovation. Major universities including Stanford, Duke, Brown, Oxford and Cambridge have established social innovation research centres, notably in Business Schools. Indeed much of the academic literature on social innovation is published in 
business management journals such as Harvard Business Review and Stanford Social Innovation Review. Leading social policy journals have largely ignored the concept, although this may change following the significant investment in cross-national research within the European Union provided by the Seventh Framework Programme $\left(\mathrm{FP}_{7}\right)$ and Horizon 2020 initiatives.

The reluctance of social policy researchers to engage with social innovation might be partly attributable to its conceptual imprecision (Pol and Ville, 2009; Massey and Johnston-Miller, 2014). In addition to disagreement as to what constitutes innovation, there are multiple uses of the term 'social' within the concept (Nicholls and Murdock, 2010), including new forms of social collaboration; collective approaches to delivering these innovations; the role of the social sector (or civil society) at different stages of the social innovation process; and the (positive) societal impact of these social innovations. It is notable though that most usages of the concept imply positive connotations (Evers et al., 2014). This conceptual imprecision is sometimes seen as permitting social innovation to be used by policymakers to disguise 'an agenda of further liberalisation and public service withdrawal' (Sinclair and Baglioni, 2014: 410). It would appear that social innovation has joined a long list of essentially contested concepts (Gallie, 1956) that have proved attractive to policy makers as they imply positive connotations while their ability to be differentially interpreted by various protagonists means that they can never be 'disproven' (Teasdale et al., 2012; Ziegler, 2015).

However, the fact that social innovation is contested, conceptually imprecise and used in ways which we may see as disagreeable should not dissuade us from engaging with the concept. Gallie's approach remains a benchmark where the goal of research is to make sense of complex concepts and to understand their evolution over time (Collier et al., 2006). Gallie (1956) outlines five main criteria in his schema of a contested concept. It is worthwhile briefly reproducing these criteria here. First, contested concepts like social innovation are appraisive - they signify a valued achievement. Second, they are internally complex - although the worth of social innovation is attributed to the whole, the internal elements are variously interpreted. Third and relatedly, the concept as a whole is variously describable by different actors. Fourth, the concept is open and amenable to change over time. Fifth, parties recognise that usage is contested. Following on from these defining criteria Gallie argues that each actor attempts to assert their own authority in defining the concept, and that this can lead to progressive competition such that the quality of arguments improves over time.

In this paper we explore the evolution of social innovation as an academic concept in order to understand 'how it came to be'. We provide a brief overview of early usages of the concept before turning to a more systematic bibliometric analysis to identify the most influential social innovation texts produced between 1989 and 2013. Our analysis traces the emergence of a more settled (and less contested) conception of social innovation, particularly since 2004, that 
appears (almost illogically) to have amalgamated key elements of preceding conceptualisations. It would appear that there has been a form of de-contestation (or collaboration - see Ziegler, 2015). Most usages now recognise the importance of new forms of social relationships (at the individual or organizational level) in generating new ideas and in delivering new solutions. In turn these (usually collaborative) solutions are assumed to have a positive societal impact. It is predominantly within this broad conception that contestation now occurs, between protagonists from a radical or strong tradition focusing on the potential of collaborative processes to restructure extant power relations, and those from a utilitarian or weak tradition whose focus is on the utilitarian social value of the innovation. In the closing section of this paper, we begin to sketch out what this means for social policy research and offer tentative ideas as to how social policy academics might take this forward.

\section{The sociological origins of social innovation}

A cursory search on Google Scholar for 'social innovation' yielded 44,100 hits on 19 May 2015. Not all of these directly engaged with social innovation as a concept - many derived from the almost coincidental bundling together of the two words 'social' and 'innovation'. However, it is clear that there is a substantive academic literature on the topic. This can be dated to the nineteenth century and the work of Gabriel Tarde on society as an increasingly networked economy whose interconnectedness led to the proliferation of new production techniques or innovations (Tarde, 1899). A decade later, the first academic journal article to mention social innovation referred to a description of 'the substitution of the West Indian plantation for the tribal and clan life of Africa' as a social innovation (Hoggan, 1909: 351). Thus the roots of the concept are sociological. Despite this common sociological heritage, the adjective 'social' is variously describable as the (social) processes leading to the innovation (Tarde, 1899) or the (societal) consequences of the innovation (Hoggan, 1909). It is notable that neither of these early usages is appraisive. Hoggan, in particular, is critical of the slave trade while Tarde's analysis of networked societies as leading to the proliferation of innovation avoids judgment on these processes. Neither author shows awareness that others have used the concept in different (or similar) ways. Thus social innovation did not meet Gallie's definition of a contested concept. Nor was the concept widely used. Indeed, only 2,190 of the 44,100 academic articles listed in Google Scholar were published before 1989, and only 4,150 before 1999. It was, therefore, not until the turn of the twenty-first century that the concept became widely used. To some extent, Gershuny (1983) can be attributed with paving the way for a new wave of social innovation literature focusing on how technological innovations might alter the mode of provision for particular functions - potentially leading to increased leisure time and enhanced 


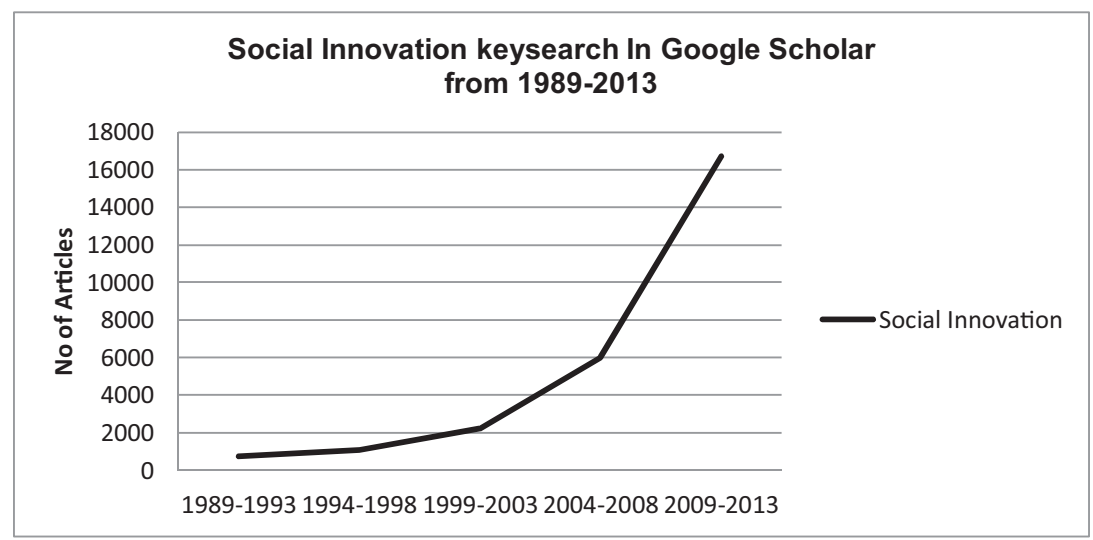

Figure 1. Growth in social innovation publications from 1989-2013.

wellbeing - but also warning of the possible impact on employment. However, the concept was to evolve so as to become almost unrecognisable to these early sociologists.

\section{Methods}

The analysis in this article was primarily undertaken between January 2014 and March 2015, and focuses on a 25-year period from 1989-2013, during which social innovation became popular in academic literature. Figure 1 shows the rapidly accelerating growth in academic articles over the time period. The sheer number of academic papers on social innovation makes it almost impossible to analyse how the concept is used in each paper. To select 'key articles' for further analysis we therefore conducted a form of bibliometric analysis to identify the most influential articles.

Bibliometric analysis can be defined as 'the application of mathematical and statistical methods to books and other media of communication' (Pritchard, 1969:348). These methods were traditionally used in libraries to describe patterns of publications within a given field or discipline (Chiu and Ho, 2005). Until recently, most bibliometric analysis of citation patterns used Thomson ISI Web of Knowledge (Harzing and Van der Wal, 2007). However, the development of Google Scholar since 2007 offers a widely utilised alternative. Whereas Web of Knowledge draws upon a core of publications assessed by in-house editors, Google Scholar uses webcrawlers to retrieve scholarly material from a (much wider) range of academic sources. This automatic inclusion process may make Google Scholar 'susceptible to indexing of non-scientific works' (Winter et al., 2014: 1548) and metadata errors such as false positive citations, duplicate citations and lack of publication year. However, its advantages include a wider coverage range which makes it particularly useful for research evaluations in 
areas not well covered by Web of Knowledge (Winter et al., 2014). As social innovation is an emergent field of research we preferred to utilise Google Scholar.

The h-index was developed by Hirsch (2005) as a relatively simple way to measure the impact of journals or academic authors. It is calculated as 'the number of papers with citation number higher or equal to $h$ '. As such, it combines both quantity (number of papers) and quality (impact, or citations to these papers) within a single number. The advancement of Google Scholar makes it simple to calculate the h-index for specific fields of interest such as social innovation. For each five-year period between 1989-2013, we identified all those publications with 'social innovation' in the title with a citation number higher or equal to h. It is important to note here that Google Scholar also permits the user to search for 'social innovation' anywhere in the publication. However this yields large numbers of articles which refer almost accidentally to 'a social innovation' rather than treating it as a concept in any meaningful way. After the removal of three duplicates, 55 publications remained consisting of 33 journal articles, nine books, four book chapters, seven reports and two working papers. Here it should be noted that the same searches conducted using Thomson ISI Web of Knowledge yielded just 20 articles, all but two of which are captured by Google Scholar (see supplementary online material).

The lead author initially read each publication to identify any definition and/or conceptualisation of social innovation. The next stage involved an inductive analysis of themes inherent within these conceptualisations. Three broad themes were identified following a second reading by the lead author: Societal Impact, Social Relations and Technological Innovation. Each publication was classified into one or more of these broad themes. The second author checked these classifications. Where disagreements occurred (five occasions) both these authors re-read the paper and discussed the classification. Following discussion both authors were able to agree on classification.

In some cases it was relatively easy to classify the papers by theme. For example for Pol and Ville (2009):

an innovation is termed a social innovation if the implied new idea has the potential to improve either the quality or the quantity of life (Pol and Ville, 2009: 881).

This definition clearly focused on the societal impact dimension of social innovation. Thus we classified it in our first category of 'societal impact'.

Most publications did not explicitly define social innovation. Indeed one paper (Introna et al., 1999) used the concept in the title and then did not refer to it again. Similarly, Henderson (1993) writes on how citizen movements contribute to social innovation, without ever specifying what is meant by social innovation. Nonetheless, a careful second reading of the paper identified a focus on how new forms of social relations between NGOs, ethnic and indigenous people, 
citizens and social movements provides creative approaches to social evolution. Here the emphasis is on the societal processes (or new forms of social relations) leading to the social innovation rather than the outcome of the innovation. Thus this paper was classified as fitting primarily into our second category of 'social relations' by virtue of bringing together new groups of people to stimulate innovation.

Within the literature analysed, the primary distinction lay between whether the authors focused on social relations or societal impact. A notable minority of the literature, however, also drew on the work of Gershuny (1983) and centred on technological innovations - while also highlighting either the social relations that led to the innovation, or the societal impact of the technological innovation. Smeds et al. (1994), for example, argued that the vacuum cleaner has a societal impact by altering the distribution of housework within the family. Thus this paper was classified as fitting into our third category of 'technological innovation and societal impact'. Alternatively, Maruyama et al. (2007) focused on how diverse actors have invested in community wind power technologies and in turn how these technologies have altered societal relations. This paper was, therefore, placed in our fourth category of 'technological innovation and social relations'.

It should also be noted that, as the concept(s) became more popular, two influential review articles were published (Pol and Ville, 2009; Howaldt et al., 2010). Both attempted to distil the various definitions into a single definition. Howaldt et al. (2010) exemplified an emergent trend to fuse the two broad approaches to understanding social innovation into a single concept - such that new forms of social relations lead to innovation, which in turn leads to societal impact. This approach is central to our final category of 'social relations and societal impact'. To some extent, many of the publications we have categorised solely under 'social relations' could have been perceived as 'social relations and societal impact', as any innovation that alters social relations will by default have a societal impact. However, we only classified those papers that explicitly referred to a significant societal impact arising as a necessary consequence of the new forms of social relations, as belonging to this final category.

While our coding proved useful as an initial classification system, and demonstrated apparent convergence in the literature over time, a problem with using broad categories was apparent. The initial coding did not distinguish between different levels of societal impact, or whether the social innovation preceded changes in social relations, or vice versa. The coding strategy also did not pick up on differences between conceptualisations which saw social innovation as a process (involving new forms of social relations for example), and those which saw it as an outcome. These differences within themes are explored and developed in the following sections. 


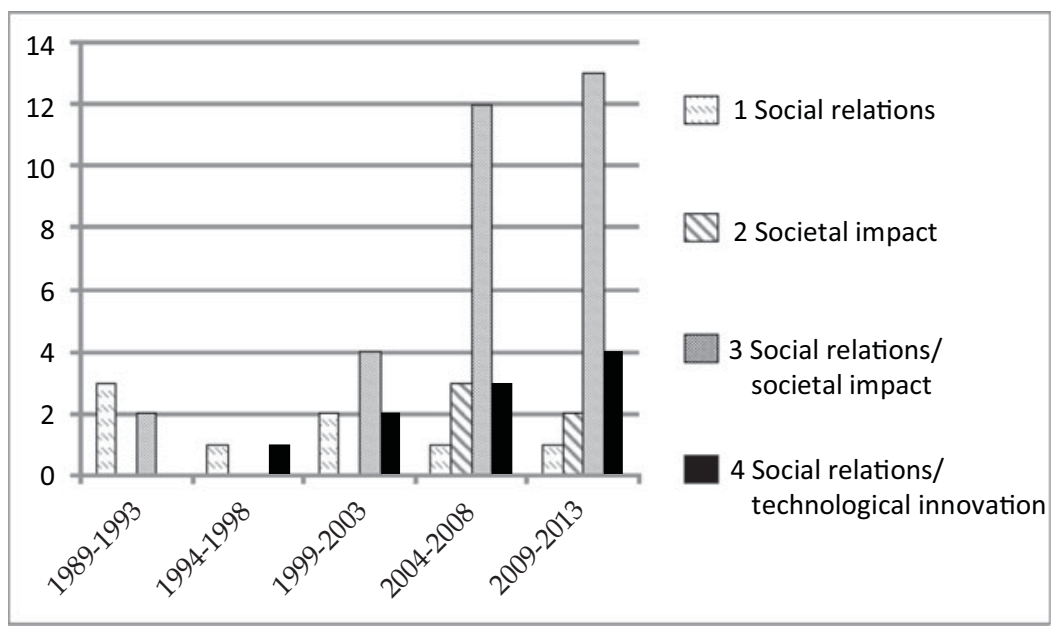

Figure 2. Evolution of the social innovation concept over time.

\section{Findings}

After classifying the publications by theme and five-year period, we were able to trace the evolution of the concept over time (see Figure 2). It is clear there are four main groups of conceptualisation: social relations, societal impact, social relations and societal impact, and social relations and technological innovation. Only one publication focused on technological innovation and societal impact. It is interesting to note the dominance of publications focusing on social relations and societal impact, particularly since 2004, such that 25 of the 39 most influential publications in this 10-year period fall into this category. However, none of the most influential publications in the first two five-year periods fell into this category. In this section we outline how the four broad conceptualisations appear to have converged over the 25 -year period.

\section{9-1993: The accidental emergence of a concept?}

In the early 1990s, the term social innovation was not widely used by many academic authors and there was little consensus around definition. Five publications during this period have since received five or more citations. The highest cited publication, by Henderson (1993), focuses on how new forms of social relations between community groups, ethnic and indigenous people, and social movements, can lead to (undefined) social innovations through pressuring dominant groups to take on board new ideas. This focus on social innovation as emerging from citizen movements remains a central aspect to much of the current social innovation literature, and was also apparent in two chapters of the book by Kraan et al. (1991). This book itself posits social innovation as deliberate socio-political change with a particular focus on innovations developed within 
civil society (Baldock and Evers, 1991; Evers, 1991; Johansson and Thorslund, 1991.) The emphasis was on how co-production of home-care with, for example, self-help groups (in the UK) and home support delivered by family members (in Sweden), could potentially transform the delivery of a wide range of health care services.

Westley (1991) provided a detailed analysis of how Bob Geldof created innovation in the music industry by virtue of (temporarily) bridging the worlds of music and famine relief. Westley focused on how visionary social leadership can affect 'global social innovation'. Here social innovation is treated as the outcome. Interestingly, given the prominence of the Live Aid case, the focus is not on societal impact but rather on how this social innovation entailed the development of new (social) relations between the music industry and the famine relief industry.

Bunker and Alban (1992) discussed whether large group interventions in organisational development practice should be envisioned as social innovations. Although the concept is barely referred to, let alone defined, the emphasis on intra-organisational dynamics suggest that the social in this context also derives from a sociological focus on social relations, albeit within, rather than between, organisations.

It is clear from this brief overview that there was little or no consensus around social innovation as a concept throughout this period. Indeed the term does not appear to have been used with any precision. None of the authors refer to any previous utilisation of the concept. Nonetheless, we can identify that most usages of the term appear consistent with an understanding of the social as embedded in social relations. There is also an emergent focus within much of this literature on the beneficial aspects of social innovation, reflecting its beginnings as an appraisive concept.

\section{4-1998: Social relations vs. technological innovation}

During this second five-year period there was still a tendency to loosely use the term 'social innovation' without any attempt to explain it - only one publication (Aichholzer, 1998) attempted to use the concept analytically. Each publication used the concept in different ways and approached it from different academic perspectives.

Sabel (1996) explored the role of 38 decentralised area-based partnerships in reducing unemployment in Ireland. The author argued that these reforms (or social innovations) were successful because they drew on innovative techniques of decentralised production, imported from Japanese industry and applied to the Irish public sector. Hence, new forms of social relations between business, civil society and local authorities might enable social innovation. 
Aichholzer (1998) conceptualised teleworking centres as social innovations, arguing that these necessarily involved a form of organisational change, a new pattern of needs satisfaction, and a new lifestyle. For Aichholzer, the defining criterion of whether a teleworking centre was a social innovation is the extent to which new forms of social relations become institutionalised. The implication was that, for technological solutions to succeed, social relations must also be transformed.

Approaching social innovation from the perspectives of gender equality and technological innovation, and drawing upon Gershuny (1983), Smeds et al. (1994) argued that technological innovation (in this instance the vacuum cleaner) led to a more equal sharing of tasks within the household. The societal impact of technological innovation - the restructuring of power relations - was, therefore, labelled as a social innovation.

\section{9-2003: Early signs of contestation}

This period marked the emergence of social innovation as a contested concept with one stream of thought focusing on new forms of social relations and how these might generate innovations. Emerging partly from within this tradition, we observed a more normative treatment of the concept which speculates that involving different groups in the generation of new ideas leads to better societal outcomes. Finally, a more technology-orientated literature continues to investigate the importance of restructuring social relations in order for technological innovations to take hold.

Waddell (1999) argued that learning occurs through cross-sector relationships between business, government and nonprofit. These collaborations, therefore, were seen to shift established mindsets and habits and lead to social innovation in service delivery.

While explicitly recognising that there are alternative uses of the concept, Mumford (2002) defined social innovation as:

the generation and implementation of new ideas about how people should organise interpersonal activities, or social interactions, to meet one or more common goals (253).

Mumford attempted to bring together three elements in his treatment of the concept: new ideas, organised social interactions, and the achievement of common goals. Like Waddell (1999), Mumford hypothesised that the generation of ideas

will require an active exchange of information and elaboration of ideas through interchange with others in a conducive climate (2002: 255).

For Mumford (2002), the 'social' in social innovation referred simultaneously to the social relations inherent in idea generation, the new social organisations or interactions these ideas generated, and the social or common goals these 
organisations sought to achieve. This treatment of the concept merged the two sets of literature on social relations and societal impact, such that social innovation occurs when new forms of social relations between disparate groups or individuals create new organisational processes that meet common goals. Here we begin to see clear links to the co-production literature that began to emerge in the early part of the twenty-first century.

Hazel and Onaga (2003) also linked social innovation to the co-creation of ideas, albeit from the discipline of psychology. The authors outlined a social innovation model that envisioned scientists working closely with those affected by social problems to develop solutions to them. This treatment of the concept was not universal. Introna et al. (1999) contributed to the literature on technological innovation and social relations and reinforced the finding of Aichholzer (1998) that technological innovations cannot take hold without similar innovations in social relations.

\section{4-2008: Progressive competition: challenging extant power relations or creating utilitarian societal value?}

Gallie (1956) suggested that, as protagonists recognise that other definitions of contested concepts exist, then progressive competition ensues as authors seek to strengthen their own definitions while denigrating others. This became particularly apparent during this period. Twelve of the $19 \mathrm{~h}$-index papers cited focused on social innovation as invoking new forms of social relations to generate new ideas and/or to tackle social problems more effectively. Many of these publications developed a radical tradition that drew upon the sociological heritage of social innovation, as involving new forms of social relations, but also focused on the re-shaping of power relations. Set against this, an emergent literature orientated towards business management adopted a more utilitarian approach, which focused on the social value created through social innovation. Although there was still a separate stream of literature on social relations and technological innovation - this was a minority conceptualisation.

Phills et al. (2008) approached the phenomenon from a business school perspective and defined social innovation as:

A novel solution to a social problem that is more effective, efficient, sustainable, or just than existing solutions and for which the value created accrues primarily to society as a whole rather than private individuals (2008: 36 ).

Significantly, this definition focused on the impact of the innovation - it had to be more 'just than existing solutions', with the value created accruing primarily to society as a whole. Although the body of the paper does refer to the exchange of ideas between non-profits, governments and businesses (40), this was seen as a recent trend in social innovation rather than a defining principle. As this publication is the most highly cited paper covered in this review it is particularly 
significant that this definition moved away from social relations and towards a utilitarian approach that focused exclusively on the societal value of the innovation.

The societal value created through social innovation was also the primary emphasis of the second and third most highly cited publications of this five-year period. Mulgan et al. (2007) and Mulgan (2006) described social innovation as:

innovative activities and services that are motivated by the goal of meeting a social need and that are predominantly developed and diffused through organisations whose primary purposes are social (2007: 8).

The authors partially avoided the need to determine whether something 'works' or not by focusing on the intention to meet social needs. Interestingly, the development and diffusion of social innovation was 'predominantly' through organisations 'which are primarily social' - as opposed to profit maximising organisations (9).

Not all those writing on social innovation were so eager to jettison the social relations aspect of the concept. Moulaert et al. $(2005 ; 2007)$ outlined a more radical concept of social innovation while also recognising the potential for neoliberal discourse to incorporate critique and accommodate it within its own logic. The implication being that the utilitarian approach adopted by Phills, Mulgan and others was symbolic of neoliberal reasoning. The authors' interest was on social innovation as a set of radical practices that together led to greater social inclusion and social justice via the changing of existing social (and particularly power) relations. This conceptualisation focused on social relations, not only as leading to (social) innovation, but also as a consequence of innovation the social inclusion of marginalised groups. From this more radical perspective, societal change necessarily involved the restructuring of power relations, and thus directly opposed the utilitarian approach. This more explicitly normative and radical approach to conceptualising social innovation was a particular feature of the period. Other articles appearing in the special issues on social innovation edited by Moulaert and colleagues (2005; 2007), unsurprisingly, adopted a similar conceptualisation (Gerometta et al., 2005; Novy and Leubolt, 2005). Similarly, Tapsell and Woods (2008) applied a Schumpeterian perspective to social innovation, arguing that social innovation should be understood as a process of dynamic change - thus involving the reconfiguring of co-operating groups (or forms of social relations).

Most of the literature emanating from this period reflected a broad consensus that new forms of social relations lead to societal change. Jegou and Manzini (2008) focused on local collaborations and mutual assistance within communities to solve problems or generate new opportunities, such as car-sharing, shared sewing studios and home restaurants. Similarly, Wheatley and Frieze (2006), Drewe et al. (2008), Leadbeater (2007), Regalia (2006), Manzini (2007), Morelli 
(2007), Pot and Vaas (2008) and Marcy and Mumford (2007) emphasised the power of networks to create social change and/or to provide solutions to social problems. In combining the social relations and societal change dimensions of social innovation within a single concept, all of these authors (albeit to varying extents) enthused these new forms of social relations with a positive reading of social change.

It should also be noted that within this period there were also three h-index papers published that emphasised the importance of new forms of social relations in driving technological innovations (Maruyama et al., 2007; Gardner et al., 2007; Taatila et al., 2006).

\section{9-2013: The apparent de-contestation of social innovation}

Our analysis of the $20 \mathrm{~h}$-index publications produced during this period suggests a convergence around an approach that combines social relations and societal impact -17 of the 20 papers were categorised in this way.

The most highly cited paper (Brown and Wyatt, 2010) linked the concept of design thinking to social innovation. Developing the premise that 'systemic problems require systemic solutions' (35), the authors argued that the involvement of a diversity of people generates new ideas for solutions, which can be implemented quickly and without fear of failure.

Murray et al. (2010) defined social innovations as:

innovations that are social both in their ends and in their means. Specifically, we define social innovations as new ideas (products, services and models) that simultaneously meet social needs and create new social relationships or collaborations. In other words, they are innovations that are both good for society and enhance society's capacity to act (3).

This is probably the clearest example of the merging of the social relations and social impact approaches to social innovation into what has become a normative discourse. Thus a social innovation necessarily involves the restructuring of social relations at both the ideational stage and during the delivery of the innovation.

Perhaps surprisingly, given that their paper drew upon an analysis of existing literature, Pol and Ville (2009) was one of only three papers not to merge the social relations and societal impact approach, instead arguing:

an innovation is termed a social innovation if the implied new idea has the potential to improve either the quality or the quantity of life (881).

This utilitarian approach was derived through their analysis of existing literature and led to their conclusion that the only common denominator from this discourse centred on the notion that social innovations improve quality of life (Pol and Ville, 2009). It would seem that, in searching for a common denominator, the authors discovered only the normative connotations inherent in much (though by no means all) of the literature. From this finding they attempted to generalise 
and create a utilitarian concept. Somewhat ironically, this has led to a definition that has become almost devoid of the meanings inherent in the competing sets of literature covered in this article.

During this period, a group of sociologists and political scientists continued Moulaert's more radical approach of conceptualising social innovation as the political transformation of society through creating new social and power relations (MacCallum et al., 2009; Moulaert, 2009; Moulaert et al., 2010). Moulaert (2009) and MacCallum et al. (2009) emphasised that the 'empowerment' of citizens was needed to satisfy their basic needs and integrate them into labour market with the help of local partnerships of civil society groups. Moulaert et al. (2010) highlighted how grassroots collaborations could transform social relations and improve governance systems in urban neighbourhoods. Moore and Westley (2011) and Antadze and Westley (2010) adopted a similar focus on social change as the restructuring of social relations with the latter defining social innovation as:

those processes, products, and initiatives which profoundly challenge the system that created the problem that they seek to address (15).

This focus on collaborations between government, social enterprises and other third sector organisations in the creation of social innovation was also followed by Goldenberg et al. (2009), Goldsmith et al. (2010). Murray et al. (2010) and Ellis (2010). To some extent, this reflects the focus of Mulgan (2006) on the diffusion of social innovation through not-for-profit organisations, albeit with an added emphasis on new forms of social relations at an intra-organisational level (similar to that identified by Baldock and Evers, 1991). This reflected a policy emphasis emerging in the United States and within the European Commission on social enterprise and non-profits as creators and diffusers of social innovation.

\section{Conclusion and avenues for future research}

We initially set out to explore how the concept of social innovation has developed over time. The concept was first used by sociologists, either to explain how increasingly networked societies stimulated technological innovations (Tarde, 1899), or to understand the societal impact of innovations (Hoggan, 1909). The subsequent social innovation literature cuts broadly across three main themes that were identifiable in these early studies: technological innovation, social relations, and societal impact. Figure 2 identified that almost all of the most cited publications since 1989 could be classified into four combinations of these themes: social relations; societal impact; social relations and societal impact; and technological innovation and social relations.

Prior to 1999, there were no clear patterns in the development of the concept(s). Much of the disparate literature derived from a sociological focus 
on social relations. A minority of publications concentrated on the processes leading to, or consequences of, technological innovations. A focus on social innovation as a process, whereby new forms of social relations lead to societal change, emerged at the turn of the millennium. This has since become the dominant broad conception, although it should be noted that a minority of the literature maintains a focus on technological change. This broad conception can be seen as a set of processes that amalgamate combinations of up to three related propositions inherent in the social innovation literature.

First, and deriving from sociological literatures, but also apparent in the literatures on technology and social change, political science, and design thinking, social innovation involves new forms of collaboration, whether at an individual or organisational level, often implying new and less hierarchical relationships between government, civil society and citizens. This subsequently leads to new ideas (or innovations). The innovation element of the concept is often left undefined but usually relates to the newness of the ideas themselves, the newness of the collaborative forms of social relations involved in both the idea generation and the implementations of these ideas. From the wider innovation literature it is also possible to distinguish between ideas and solutions which are wholly new; those that are imported from an alternative space; and those that involve gradual and incremental improvement of existing solutions (see Osborne, 2013).

Second, and deriving from the literatures on technology and social change, and from political science, these innovations can lead to a restructuring of social and/or extant power relations in the way they are implemented. Alternatively, a third proposition deriving from the business and management literature is that the innovation should have a positive societal impact through its utilitarian value - improving the quality or quantity of life (Pol and Ville, 2009).

Figure 3 illustrates the social innovation process. The academic literature details five plausible routes through some or all of this process, all of which can be conceived of as social innovation. First, new forms of social relations lead to innovation; second, innovation leads to a restructuring of social and or power relations; third, innovation leads to utilitarian social value; fourth, new forms of social relations lead to innovation which results in the restructuring of power relations (and thus societal impact); and fifth, new forms of social relations lead to innovation, which creates utilitarian social value (and thus societal impact).

Key differences within the literature are, firstly, whether collaboration is a necessary element in the social innovation process and, secondly, whether social innovation is a process, or merely the utilitarian value created from any innovation. These differences highlight the disparity between a more radical and normative tradition which sees social (and political) change occurring as a consequence of innovations in social relations (demonstrated by the bold arrows in Figure 3), and a more utilitarian approach which emphasises the societal impact of any innovation as defined by changes in aggregate individual utility 


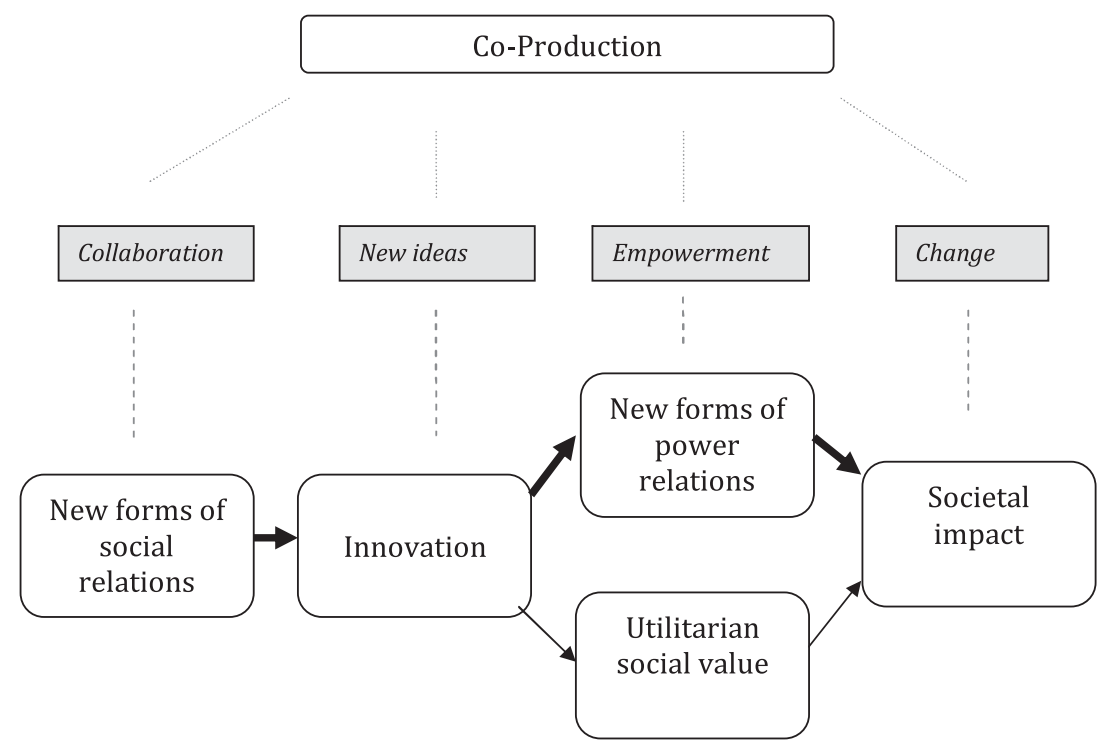

Figure 3. Social innovation pathways and drawing the link to co-production.

(demonstrated by the thinner arrows in Figure 3). The radical tradition, herein termed strong social innovation, bears a strong resemblance to co-production, which itself is helpful in breaking down the constituent parts of the strong social innovation process.

While a wide range of actions can be classified under this umbrella term of co-production, the common themes underpinning these fall within the parameters of collaboration, the generation of new ideas, empowerment and societal change (Bovaird and Loeffler, 2012; Brandsen and Pestoff, 2006). We suggest that co-production can be conceptually linked to more radical models of social innovation as in Figure 3. Proponents of co-production invoke the notion of empowerment as a key element of this way of working (Pestoff, 2006). The strong tradition of social innovation can be seen, therefore, to invoke the synonymous narrative of restructured power relations through the engagement and empowerment of previously disadvantaged individuals and groups. While both social innovation traditions have social change as the final outcome, for the weak tradition social change is limited to aggregate changes in individual utility (Pol and Ville, 2009) as opposed to the shifting balance of power inherent in the strong tradition (Moulaert et al., 2010).

Social innovation, as conceptualised in the literature, should be seen as a process, and one that has inherently political dimensions. This process does not occur in a vacuum. Social policy research needs to understand how the combination of different groups in the generation of ideas and solutions affects outcomes for these groups and wider societies. This is difficult to achieve using 
retrospective analysis of 'successful' social innovations. Longitudinal studies, that begin to unpack the power dimensions within these new forms of collaboration, demonstrate much potential (Evers et al., 2014).

But it is at the macro level where opportunities for more critically focused social policy research open up. Here social innovation policy agendas might be explored within their wider contexts - to what extent is social innovation used as a smokescreen for cuts in public service delivery - for example by tracing expenditure flows. Cross-country comparisons between countries engaging in social innovation approaches can build on the work of European Union funded projects, such as Creating Economic Space for Social Innovation (CRESSI), which study institutional and policy environments for social innovation at the local level. Research might explore 'under what circumstances might greater citizen and civil society engagement in the collaboration and empowerment stages produce different societal outcomes?'

Regional comparisons offer an alternative fruitful approach. Social innovation as a means of modernising welfare states is at different stages of adoption and development in different countries. These approaches might usefully be studied to identify differences and similarities by, for example, welfare regime type and with a particular emphasis on differences between strong and weak traditions. It is important to avoid focusing research solely on western countries. In developing countries, which do not have developed welfare states, social innovation might be seen as a means of bypassing the need for welfare state development. But given the very different relationships between state, civil society and citizens in these areas it remains to be seen whether, and how, more authoritarian governments can build closer and less hierarchical relationships between these groups.

\section{Supplementary material}

To view supplementary material for this article, please visit http://dx.doi.org/ 10.1017/Soo4727941600009X

\section{References}

Aichholzer, G. (1998), 'A Social Innovation in Its Infancy: Experiences with Telework Centres,' in P. Jackson and J. M. van der Wielen (eds.), Teleworking: International Perspectives. From Telecommuting to the Virtual Organisation, London: Routledge, pp. 293-302.

Antadze, N. and Westley, F. (2010), 'Funding social innovation: how do we know what to grow?', The Philanthropist, 23: 3, 343-356.

Baldock, J. and Evers, A. (1991), 'On social innovation: a short introduction', in R. J. Kraan, J. Baldock, B. Davies, A. Evers, L. Johansson, M. Knapen, M. Thorslund, C. Tunissen, (eds.), Care for the Elderly. Significant Innovations in Three European Countries, Frankfurt: Campus Verlag, pp. 87-92.

Bovaird, T. and Loeffler, E. (2012), 'From engagement to co-production: how service users and communities contribute to public services', in V. Pestoff, T. Brandsen and B. Verschuere 
(eds.), New Public Governance, the Third Sector and Co-production, London: Routledge, pp. 35-60.

Brandsen, T. and Pestoff, V. (2006), 'Co-production, the third sector and the delivery of public services', Public Management Review, 8: 4, 493-501.

Brown, T. and Wyatt, J. (2010), 'Design Thinking For Social Innovation', Stanford Social Innovation Review, 8: 1, 30-35.

Bunker, B. and Alban, B. T. (1992), 'Editors' introduction: the large group intervention - a new social innovation?', Journal of Applied Behavioral Science, 28: 4, 473-479.

Chiu, W. T. and Ho, Y. S. (2005), 'Bibliometric analysis of homeopathy research during the period of 1991 to 2003', Scientometrics, 63: 1, 3-23.

Collier, D., Hidalgo, F. D. and Maciuceanu, A. O. (2006), 'Essentially Contested Concepts: Debates and Applications', Journal of Political Ideologies 11: 3, 211-246.

Drewe, P., Klein, J. I. and Hulsbergen, E. (2008), The Challenge Of Social Innovation in Urban Revitalization, Amsterdam: Techne Press.

Ellis, T. (2010), The New Pioneers: Sustainable business success through social innovation and social entrepreneurship. New York: Wiley.

Evers, A. (1991), 'Introduction', in R. J. Kraan, J. Baldock, B. Davies, A. Evers, L. Johansson, M. Knapen, M. Thorslund, C. Tunissen (eds.), Care for the Elderly-Significant Innovations in Three European Countries, Frankfurt: Campus-Verlag, pp. 1-6.

Evers, A., Ewert, B. and Brandsen, T. (2014), Social innovations for social cohesions, Liege: EMES European Research Network, http://www.wilcoproject.eu/ downloads/WILCO-project-eReader.pdf.

Gallie, W. B. (1956), 'Essentially Contested Concepts', Proceedings of the Aristotelian Society, 56 (1955-1956), 167-98.

Gardner, C., Acharya, T. and Yach, D. (2007), 'Technological and Social Innovation: A Unifying New Paradigm For Global Health', Health Affairs, 26: 4, 1052-1061.

Gerometta, J., Häussermann, H. and Longo, G. (2005), 'Social innovation and civil society in urban governance: Strategies for an inclusive city', Urban Studies, 42: 11, 2007-2021.

Gershuny, J. (1983), Social innovation and the division of labour, Oxford: Oxford University Press.

Goldenberg, M., Kamoji, W., Orton, L. and Williamson, M. (2009), Social innovation in Canada: An update, CPRN Research Report.

Goldsmith, S., Georges, G. and Glynn Burke, T. (2010), The Power of Social Innovation: How Civic Entrepreneurs Ignite Community Networks for Good, San Francisco: Jossey Bass.

Harzing, A. W. and Van der Wal, R (2007), 'Google Scholar: the democratization of citation analysis?', Ethics in Science and Environmental Politics, 8: 1, 61-73.

Hazel, K. L. and Onaga, E. (2003), 'Experimental social innovation and dissemination: the promise and its delivery', American Journal of Community Psychology, 32: 3-4, 285-94.

Henderson, H. (1993), 'Social innovation and citizen movements', Futures, 25: 3, 322-338.

Hirsch, J. E. (2005), 'An index to quantify an individual's scientific research output', Proceedings of the National Academy of Sciences, 102, 46, 16569 - 16572.

Hoggan, F. (1909), 'The American negro and race blending', The Sociological Review, 2: 4, 349-360.

Howaldt, J. and Schwartz, M. (2010), 'Social Innovation: Concepts, Research Fields and International Trends', in K. Henning, F. Hees (eds.), Studies for Innovation in a Modern Working Environment - International Monitoring, 5, Aachen: IMA/ZLW\&IfU.

Introna, L. D., Moore, H. and Cushman, M. (1999), 'The Virtual Organisation - Technical or Social Innovation? Lessons from the Film Industry', Working Paper Series, London: Department of Information Systems, London School of Economics and Political Science.

Jegou, F. and Manzini, E. (2008), 'Collaborative Services: Social Innovation and Design for Sustainability', Milano: poli.design.

Johansson, L. and Thorslund, M. (1991), 'The national context of social innovation - Sweden', in R. J. Kraan, J. Baldock, B. Davies, A. Evers, L. Johansson, M. Knapen, M. Thorslund, 
C. Tunissen (eds.), Care for the Elderly-Significant Innovations in Three European Countries, Frankfurt: Campus-Verlag, pp. 28-44.

Kraan, R. J., Baldock, J., Davies, B., Evers, A., Johansson, L., Knapen, M., Thorslund, M. and Tunissen, C. (eds.) (1991), Care for the Elderly-Significant Innovations in Three European Countries, Frankfurt: Campus-Verlag.

Leadbeater, C. (2007), 'Social enterprise and social innovation: Strategies for the next ten years: A social enterprise think piece for the Office of the Third Sector', London: Cabinet Office of the Third Sector.

MacCallum, D., Moulaert, F., Hillier, J. and Haddock, S., V. (2009), Social Innovation and Territorial Development, Aldershot: Ashgate.

Manzini, E. (2007), 'Design Research for Sustainable Social Innovation', in R. Michel (ed.), Design Research Now: Essays and Selected Projects, Basel, Switzerland: Birkhäuser.

Marcy, R. T. and Mumford, M. D. (2007), 'Social Innovation: Enhancing Creative Performance Through Causal Analysis', Creativity Research Journal, 19: 2-3, 123-140.

Maruyama, Y., Nishikido, M. and Lida, T. (2007), 'The Rise Of Community Wind Power In Japan: Enhanced Acceptance Through Social Innovation', Energy Policy, 35: 5, 2761-2769.

Massey, A. and Johnston-Miller, K. (2014), 'Governance: public governance to social innovation', Policy \& Politics, Fast-track Article, July 2014.

Moore, M. and Westley, F. (2011), 'Surmountable Chasms: Networks and Social Innovation for Resilient', Ecology and Society, 16: 1, 5.

Morelli, N. (2007), 'Social Innovation and New Industrial Contexts: Can Designers Industrialize Socially Responsible Solutions', Design Issues 23: 4, 3-21.

Moulaert, F. (2009), 'Social Innovation: Institutionally Embedded, Territorially (Re)produced', in MacCallum, D., Moulaert, F., Hillier, J., Haddock, S., V. (eds.), Social Innovation and Territorial Development, London and New York: Ashgate.

Moulaert, F., MacCallum, D., Mehmood, A., Hamdouch, A., Hillier, J. and Beinstein, B. (2010), 'Social Innovation: Collective action, social learning and transdisciplinary research. Final Report: Towards a Handbook', KATARSIS 029044, 1-220.

Moulaert, F., Martinelli, F., Gonzalez, S. and Swyngedouw, E. (2007), 'Introduction: Social Innovation and Governance in European Cities: Urban Development Between Path Dependency and Radical Innovation', European Urban and Regional Studies, 14: 3, $195-209$.

Moulaert, F., Martinelli, F., Swyngedouw, E. and Gonzalez, S. (2005), 'Towards alternative model(s) of local innovation', Urban Studies, 42: 11, 1969-1990.

Mulgan, G. (2006), 'The Process of Social Innovation', Innovations: Technology, Governance, Globalization, 1: 2, 145-162.

Mulgan, G., Tucker, S., Ali, R. and Sanders, B. (2007), 'Social Innovation: What It Is, Why It Matters and How It Can Be Accelerated', Working Paper: Skoll Centre for Social Entrepreneurship.

Mumford, M. D. (2002), 'Social Innovation: Ten Cases from Benjamin Franklin', Creativity Research Journal, 14: 2, 253-266.

Murray, R., Grice, J. C. and Mulgan, G. (2010), The Open Book of Social Innovation. The Young Foundation \& NESTA.

Nicholls, A. and Murdock, A. (2010), 'The nature of social innovation', in Nicholls, A. and Murdock, A. (eds.), Social Innovation: Blurring Boundaries to Reconfigure Markets, Palgrave Macmillan UK, pp. 1-30.

Novy, A. and Leubolt, B. (2005), 'Participatory budgeting in Porto Alegre: Social innovation and the dialectical relationship of state and civil society', Urban Studies, 42: 11, 2023-2036.

Osborne, S. P. (2013), Voluntary organizations and innovation in public services, London: Routledge.

Pestoff, V. (2006), 'Citizens and co-production of welfare services', Public Management Review, $8: 4,503-519$.

Phills, J. A., Deiglmeier, K. and Miller, D. T. (2008), 'Rediscovering Social Innovation.', Stanford Social Innovation Review, 6: 4, 34-43. 
Pol, E. and Ville, S. (2009), 'Social innovation: Buzz word or enduring term?', The Journal of Socio-Economics, 38: 6, 878-885.

Pot, F. and Vaas, F. (2008), 'Social innovation, the new challenge for Europe', International Journal of Productivity and Performance Management, 57: 6, 468-473.

Pritchard, A. (1969), 'Statistical bibliography or bibliometrics', Journal of Documentation, 25: 4, 348-9.

Regalia, I. (2006), 'Regulating New Forms of Employment: Local Experiments and Social Innovation In Europe', London: Routledge.

Sabel, C (1996), 'Ireland. Local partnerships and social innovation', Paris: OECD.

Sinclair, S. and Baglioni, S. (2014), 'Social Innovation and Social Policy - Promises and Risks', Social Policy and Society, 13: 03, 469-476.

Smeds, R., Huida, O., Haavio-Mannila, E. and Kauppinen-Toropainen, K. (1994), 'Sweeping Away the Dust of Tradition: Vacuum Cleaning as a Site of Technical and Social Innovation', in C. Cockburn and R. Fürst-Dilič (eds.), Bringing Technology Home, Buckingham: Open University Press, pp. 22-41.

Taatila, V. P., Suomala, J., Siltala, R. and Keskinen, S. (2006), 'Framework to study the social innovation networks', European Journal of Innovation Management, 9: 3, 312-326.

Tapsell, P. and Woods, C. (2008), 'A Spiral of Innovation Framework for Social Entrepreneurship: Social Innovation at the Generational Divide in an Indigenous Context', Emergence: Complexity and Organizations, 10: 3, 25-34.

Tarde, G. (1899), Social laws: An outline of sociology, New York: Macmillan.

Teasdale, S., Alcock, P. and Smith, G. (2012), 'Legislating for the big society? The case of the Public Services (Social Value) Bill', Public Money \& Management, 32: 3, 201-208.

Waddell, S. (1999), 'Business-government-nonprofit collaborations as agents for social innovation and learning', paper presented at the meeting of the Academy of Management, Chicago.

Westley, F. (1991), 'Bob Geldof and Live Aid: The Affective Side of Global Social Innovation', Human Relations, 44: 10, 1011-1036.

Wheatley, M. and Frieze, D. (2006), 'Using Emergence to Take Social Innovation To Scale', Provo, UT: The Berkana Institute.

Winter, D. J. C., Zadpoor, A. A. and Dodou, D. (2014), 'The expansion of Google Scholar versus Web of Science: a longitudinal study', Scientometrics, 98: 2, 1547-1565.

Ziegler, R. (2015), 'Social innovation as a collaborative concept', International Social Innovation Research Conference, York, September 2015. 